\title{
El nacimiento en la biopolítica: la génesis de la vida en Hegel y Deleuze
}

\author{
The birth in biopolitics: The genesis of life \\ in Hegel and Deleuze
}

JULIÁN FERREYRA*

\begin{abstract}
Resumen: Este artículo indaga el aporte que el concepto de nacimiento puede realizar al debate en torno de la biopolítica, en tanto no se lo considere como una figura de la reproducción mecánica, sino como una fisura en la trama de la causalidad empírica. Para desarrollar esta perspectiva, se confrontará el rol del nacimiento en los conceptos de vida en Deleuze y Hegel. El concepto de nacimiento así configurado se aplicará a las problemáticas de la biopolítica de manera en que ésta, en lugar de ser meramente un conjunto de tecnologías o mecanismos para la conservación de las relaciones de producción específicas del capitalismo, revele su faz positiva, y sea capaz de introducir nuevas relaciones individuales y sociales.
\end{abstract}

Palabras clave: nacimiento, biopolítica, vida, Deleuze, Hegel.

\begin{abstract}
This paper researches the contribution of the concept of birth to the debate on biopolitics, as long as birth is not considered as a figure of the mechanical reproduction but as a rupture on the weft of empirical causality. In order to achieve so, the function of birth in the concepts of life of Deleuze and Hegel will be confronted. A conception of birth in biopolitics will be thus constructed, where, instead of just being an aggregate of technologies and mechanisms for maintaining the capitalist relations of production, it would reveal it positive face, where it's able to introduce new individual and social relationships. Keywords: Birth, biopolitics, life, Deleuze, Hegel.
\end{abstract}

a juan cruz, mi espejo al país de las maravillas

¿De dónde proviene lo que de pronto está ahí entre nosotros?

Un padre mira a su bebé recién nacido. Se refleja en él. Espejo singular, perturbador, desformante. La zoncera del sentido común le dice: «se parece a vos». Y él quiere creerle. Quién no quiere creerle al sentido común. Es tan tranquilizador. No obstante, el espejo

Fecha de recepción: 04/12/2012. Fecha de aceptación: 15/02/2013.

* Investigador del CONICET (Argentina) y docente de Antropología Filosófica en la Universidad de Buenos Aires. djulianferreyra@gmail.com. Investiga la relación entre Deleuze y Hegel, tanto en el plano ontológico como en sus necesarias implicancias prácticas. Autor de «Ideas, from Hegel to Deleuze», Comparative and Continental Philosophy, Londres, 4.1 (2012), pp. 93-104 y L'ontologie du capitalisme chez. Gilles Deleuze (2010), Paris: L'Harmattan. 
ontológico le devuelve una imagen que, definitivamente, no se parece a él. Y sin embargo es él. Sin calma, identidad o equivalencia, en esta reflexión las imágenes se desacoplan. Este estadio del espejo no está sin embargo en la base de ninguna agresividad. No hay drama ni insuficiencia, sino por el contrario la posibilidad de que la vida engendre más vida. No, no se parece a él - es el espejo de Alicia, y en él se asoma al otro lado: una sonrisa, un gesto, una mueca, acontecimientos que no son caracteres subjetivos. El, determinación empírica, se asoma al mundo de las determinaciones de la inmanencia. En ese sentido, el bebé es la idea existente en sí y para sí.

De pronto está ahí entre nosotros. ¿Qué fue lo que pasó? ¿De dónde proviene? No de una cadena de causas y efectos. Eso pasó: el fuego encontró al agua y ahora puedo tomar este mate caliente. Pero no. La experiencia del nacimiento desgarra el orden extensivo. Ante la beatitud de ese bebé entre los brazos la pregunta por lo que pasó se vuelve sorda a las meras causas eficientes. Necia en el nacimiento. Lo impensable está aquí. Esta vida, aquí, que no es la mía, ni la nuestra, sino esta vida, personal pero arrancada a las individualidades en juego. Sustraída al eterno flipper del mecanicismo. De pronto. De hecho. ¿Cómo es posible? ¿Cuáles son las condiciones de posibilidad de lo que, de hecho, es posible? Pero esta vida, aquí, que no es la mía, no sólo desborda la causalidad mecánica, sino también el viejo truco kantiano de las condiciones de posibilidad. Desborda así la proyección de lo que de hecho es sobre lo que simplemente lo haría posible. A partir de un estudio diferencial de las filosofías de G.W.F. Hegel y Gilles Deleuze intentaremos pensar el nacimiento por fuera de los ardides de la causalidad mecánica, del fundamento y de las condiciones de posibilidad. No se trata de saber cómo es posible esta vida que de pronto está aquí entre nosotros, sino cómo es real. ${ }^{1}$ Se trata de superar el punto de vista del condicionamiento y lograr alcanzar el punto de vista de la génesis. ${ }^{2}$

Mucho se ha hecho en filosofía para conceptualizar aquello que desborda las categorías con las que aparentemente pensamos. Mucho, sobre todo, desde la perspectiva tanatológica. ${ }^{3}$ Ejemplo entre los ejemplos: el ser-para-la-muerte heideggeriano. Los autores que proponemos poner en juego en estas páginas no son, en absoluto, ajenos a este gesto mortuorio eminente de la filosofía. La muerte es un tema sin duda en Hegel y lo es también en Deleuze. Pero ya basta de la muerte. Preferimos pensar aquí lo impensable en el nacimiento. La reproducción de la vida es por un lado la repetición de lo mismo (el viviente que se pone como idéntico a sí mismo y conserva así su especie), pero por el otro un desgarro en el tejido de la continuidad mecánica — el síntoma de que las determinaciones empíricas están íntimamente ligadas a otro orden de determinación: lo que llamaremos, siguiendo a Deleuze, determinación de la inmanencia o determinabilidad trascendental.

1 Cfr. G. Deleuze: Différence et répétition, Paris, PUF, 1968, p. 273, la traducción es mía y G.W.F. Hegel: Enciclopedia de las ciencias filosóficas, trad. cast. de R. Valls Plana, Alianza, Madrid, 1997, p. 234.

2 Cfr. Deleuze, op. cit. p. 221.

3 «No ha habido ningún compromiso sustancial de la filosofía con el nacimiento hasta este momento. La filosofía comienza considerando la muerte y la finitud, y habitualmente termina con estos temas. El nacimiento es, para la mayoría de los filósofos nada más que un prerrequisito necesario para una vida que por lo demás se dirige hacia la muerte, un prerrequisito que siempre está ya dado y que por lo tanto no necesita más consideración», A. Boelderl: «A philosophy of birth? Psychohistory as a cultural theory», Dialogue \& Universalism, vol. 9, issue 11/12, 1999, pp. 29-47, p. 29. 
No pretendemos hacer aquí un rastreo ni una fundamentación general de la posibilidad de una filosofía del nacimiento. Ante la vastedad de la problemática, se impone la necesidad de un recorte. Tomaremos como hilo conductor el debate contemporáneo de la biopolítica. Se trata de un debate que se origina en los estudios realizados por Michel Foucault en la segunda mitad de la década del 70 (en el primer tomo de la Historia de la sexualidad y los cursos y entrevistas de ese período). Esa construcción originaria del concepto de biopolítica (su nacimiento) tiene una fuerte carga crítica. En efecto, el énfasis foucaultiano está puesto en la biopolítica como tecnología o dispositivo para gerenciar la vida y regular la población. El nacimiento es en ese contexto uno de los objetos de intervención de la biopolítica, ${ }^{4}$ que se ocupará de acoplarlo a las necesidades de reproducción de las fuerzas vitales derivadas de las exigencias de la sociedad capitalista. Más vida para más capital, más fuerza de trabajo para más medios de producción. ${ }^{5}$

La biopolítica es una política del nacimiento, pero en tanto reproducción mecánica de las fuerzas productivas. «Al viejo derecho de hacer morir y dejar vivir se ha sustituido un poder de hacer vivir o de rechazar hacia la muerte». ${ }^{6}$ Esta primera definición de biopolítica debe ser leída, entonces, en su contexto, con una carga crítica: ese hacer vivir implica una violencia sobre los cuerpos y los individuos, una instancia de sometimiento. Contra la letra de Foucault, y apoyados en un trayecto a través de Deleuze y Hegel, intentaremos en estas páginas leer el nacimiento en la biopolítica en una tónica positiva: como un hacer vivir en tanto posibilidad de interrupción del flujo de la reproducción mecánica y creación de nuevas posibilidades de vida (rechazando hacia la muerte las condiciones del capitalismo aparentemente triunfador). Nacimiento en sentido estricto ${ }^{7}$.

\section{El nacimiento en Deleuze: Una vida como principio de toda vida}

Inmanencia: una vida... Breve, conciso, cuasi-póstumo. Críptico, plagado de referencias (a la historia de la filosofía, a la literatura, a la filosofía de Deleuze mismo). Una vida. No la vida, no esta o aquella vida, sino una vida impersonal, es lo que Deleuze trata de construir como campo trascendental («el artículo indefinido como índice de lo trascendental»). Tratando de pensar en qué consiste esa vida impersonal, el ejemplo tomado de Dickens (Riderhood, el canalla de El amigo común agonizando) ${ }^{8}$ nos encandila. Es el motivo de la muerte como abrasivo. En efecto, para pensar una vida, pensamos el momento en que

4 «La proliferación, los nacimientos y la mortalidad, el nivel de salud, la duración de la vida, la longevidad con todas las condiciones que pueden hacerlas variar; su toma a cargo se opera por toda una serie de intervenciones y controles reguladores: una bio-política de la población», M. Foucault: Histoire de la sexualité, 1, La volonté de savoir, Paris, Gallimard, 1976 p. 183.

5 Cfr. Foucault, op. cit. p. 185-188.

6 Foucault, op. cit. p. 181.

7 Este desplazamiento en el debate de la biopolítica, ha sido de alguna manera señalado por Roberto Esposito. No sólo por sus esfuerzos (más o menos afortunados) de construir una «biopolítica afirmativa», sino por haberle dedicado uno de los apartados de su Bios, biopolítica y filosofía a la cuestión del nacimiento. En esas páginas Esposito muestra cómo, si bien el nacimiento emerge en el campo de la biopolítica como variante de la tanatopolítica en tanto supresión anticipada del nacimiento en el nazismo, puede ser leído como posibilidad de creación de vida. Cfr. R. Esposito: Bíos, Biopolitica e filosofía, Torino, Einaudi, 2004, pp. 185-199.

Cfr. Ch. Dickens: Our Mutual Friend, London, Pinguin, 1997. 
Riderhood se desliza hacia la muerte que parece inevitable. ${ }^{9}$ La inminencia de la muerte disuelve los rasgos personales (desagradables, odiosos en este caso particular) y nos permite asomarnos al campo trascendental. Alcanzamos la beatitud, al costo de disolvernos en un sinfondo informe. ${ }^{10}$ Esta perspectiva (pensar lo impersonal como el perecer de lo personal) es una condena para el pensamiento. Toda reflexión posterior, todo desarrollo de tal grito filosófico sólo podrá ser una marcha fúnebre. Sin embargo, este ejemplo viene acompañado de otro grito, que desarrolla un verdadero canto: el ejemplo de los bebés.

Las singularidades o los acontecimientos constitutivos de una vida coexisten con los accidentes de la vida correspondiente, pero no se agrupan ni se dividen de la misma manera (...) Por ejemplo, todos los bebés se parecen y no tienen casi individualidad; pero tienen singularidades, una sonrisa, un gesto, una mueca, acontecimientos que no son caracteres subjetivos. Los bebés están atravesados de una vida inmanente que es pura potencia, e incluso de beatitud a través de los sufrimientos y las debilidades (...) El indefinido como tal no marca una indeterminación empírica sino una determinación de inmanencia o una determinabilidad trascendental. ${ }^{11}$

El camino de la muerte nos llevaba a poner el énfasis en la disolución de las determinaciones empíricas: de allí el peligro de la indiferencia (el gran peligro para la filosofía deleuziana: que la filosofía de la diferencia se transforme en filosofía de la indiferencia). En el contexto del ejemplo Riderhood una vida es caracterizada por su neutralidad, por encontrarse más allá del bien y del mal. Muerto, todo me da lo mismo. En el ejemplo de Riderhood una vida juega con la muerte, se dirige a la disolución en el sinfondo. Pero en el contexto del ejemplo de los bebés, una vida juega con el nacimiento. La argumentación se dirige así hacia la «determinación de la inmanencia o la determinabilidad trascendental», es decir, cómo el campo trascendental de la inmanencia no es sólo sinfondo sino también principio de individuación (sinfondo indeterminado pero determinable).

El camino del nacimiento nos permite reflexionar sobre la diferencia entre las determinaciones empíricas (accidentes de la vida) y las determinaciones de la inmanencia (singularidades y acontecimientos constitutivos de una vida). Porque en la muerte las determinaciones empíricas se disuelven. Punto. Son entonces puramente neutras. En el nacimiento en cambio no hay neutralidad, sino Diferencia. Las determinaciones de inmanencia y las empíricas se entrelazan. Coexisten, aunque «no se agrupan ni dividen de la misma manera». Es cierto que los bebés son ejemplo de una vida que prescinde también de toda individualidad. Pero esta prescindencia no tiene el carácter terminal del ejemplo de Riderhood. Los bebés no tienen casi individualidad, dice Deleuze. Este casi apunta al juego de una vida no ya con la muerte

9 «Entre su vida y su muerte, hay un momento en que no es más que el de una vida jugando con la muerte», G. Deleuze: «L'immanence, une vie», en: Deux régimes de fous, Paris, Minuit, 2003, pp. 359-363, la traducción es mía. p. 361.

10 Cfr. las críticas de Hegel a Spinoza en el pasaje de la esencia al concepto (G.W.F. Hegel: Enzyklopädie der philosophischen Wissenschaften I, Die Wissenschaft der Logik, en Werke 8, Frankfurt, Suhrkamp, 1970, pp. 295-297, 304, 306).

11 Deleuze, op. cit. p. 362. 
sino con el nacimiento. En la beatitud del rostro de los bebés se observa el momento de la génesis donde una vida abre paso a la vida.

Haciendo gala de gran incorrección política a los ojos de cualquier padre embelesado con la individualidad de su recién nacido, Deleuze afirma que todos los bebés se parecen. Más allá de la aprensión narcisista, lo que Deleuze está constatando es que desde el punto de vista de la percepción, los bebés se asemejan; parecen ser repeticiones de lo mismo. Extrínsecamente indiscernibles. Entrar en la discusión empírica (como Leibniz llevando a las damas de la corte a pasear por el jardín para ver que no hay dos hojas de árbol iguales entre sí), nos aleja de la cuestión de fondo: la diferencia intrínseca, en el plano de inmanencia. Los bebés, aún pareciendo todos idénticos, son la pizarra donde se dibujan las singularidades. El campo es unívoco; las multiplicidades que brotan en él, infinitas. En sus bebés los padres se asoman al ser como principio de toda vida: quizás sea esa la clave del desmesurado embelesamiento de los padres:

Vida y beatitud son, en realidad, una sola y misma cosa, pues la vida es amor. Es el amor, en efecto, quien desdobla el ser — que sería sin él un en sí muerto—, porque lo pone cara a cara consigo mismo, de manera que tiene la intuición y la conciencia de sí y deviene así un yo, principio de toda vida. El amor liga luego de la manera más íntima el ser y la imagen que refleja, uniendo al mismo tiempo el yo así dividido, que, sin amor, se contemplaría fríamente y sin interés. Esta nueva unidad donde subsiste eternamente la dualidad es la vida. ${ }^{12}$

Estamos enamorados de la inmanencia y no del orden extensivo. Es en la inmanencia donde el padre se refleja y ese amor es la unidad de la vida y de una vida. En el ciego orden de las causas, no hay amor, sino sólo causalidades mecánicas. Un ser muerto. Los bebés existen en toda teoría, pero pueden considerarse repeticiones de lo mismo: reproducción. Yo puedo contemplar a mi bebé como mi reproducción; pero eso no es en sentido propio amor. Fríamente y sin interés. No hay amor en la mera reproducción de las fuerzas productivas. El amor, en cambio, señala justamente el aspecto del nacimiento que excede lo meramente reproductivo: su lazo con el ser como principio de toda vida. Este íntimo lazo es el que impide que entre la vida y una vida, entre lo empírico y lo trascendental, se alce una brecha insalvable, y permite articularlos en un todo concreto. Hacer vivir. Esta articulación es la que impide que el sinfondo lo devore todo, y, por el contrario, sea concebido como principio genético.

El lazo entre la determinabilidad trascendental y la determinación empírica es inherente a uno de los conceptos fundamentales de Diferencia y repetición: la Idea (elección terminológica significativa, ya que explicita el vínculo entre la ontología deleuziana y una larga tradición filosófica que incluye al idealismo alemán). En la exposición de la teoría de la Idea, Deleuze enfatiza su estructura tripartita: $1^{\circ}$ indeterminación (empírica) de los elementos (singularidades); $2^{\circ}$ determinación recíproca de estos elementos como sistema de relaciones ideales; $3^{\circ}$ actualización en relaciones espacio-temporales y términos. ${ }^{13} \mathrm{En}$

12 M. Gueroult: «Introduction», en: J. Fichte, Initiation à la vie bienheureuse, Paris, Aubier, 5-94, 1944, p. 9, referido a pie de página por Deleuze en «La inmanencia: una vida...». Se trata de la introducción a la Iniciación a una vida feliz de Fichte.

13 Cfr. Deleuze, op. cit. p. 237. 
La inmanencia: una vida... Deleuze señala la indeterminación empírica de las singularidades, refiriéndose al primer punto. Esa indeterminación hace posible «la manifestación de la diferencia liberada de toda subordinación». ${ }^{14}$ Este es el aspecto de beatitud, «más allá del bien y del mal». ${ }^{15}$ Considerado en forma aislada, implica el aniquilamiento de toda vida, su disolución en el sinfondo. Identificada con esa perspectiva parcial, la filosofía de la diferencia se transformaría en filosofía de la indiferencia (su ruina, su terrible ruina). Pero es sólo un aspecto de los tres que caracterizan y condicionan la Idea deleuziana: el segundo es la determinación recíproca de esos elementos (las singularidades). Deleuze aclara explícitamente que esta determinación debe ser definida intrínsecamente, para diferenciarla de las relaciones espacio-temporales inmersas en un espacio uniforme. $\mathrm{La}$ indiferencia es una propiedad de las individualidades espacio-temporales pensadas por el entendimiento abstracto con prescindencia de las singularidades que encarnan. Pero no de las relaciones ideales. En la necesidad del vínculo recíproco de los elementos ideales radica la «determinabilidad trascendental».

El costo de distinguir la determinabilidad trascendental (relación recíproca de las singularidades) de la empírica (relación extrínseca de los elementos espacio-temporales) podría ser el establecimiento de una brecha ontológica entre ambas. Evitar la apertura de tal zanja es el rol de la tercera condición de las multiplicidades: encarnar. Momento del surgimiento: la idea no surge sin actualizarse y «ponerse» como vida concreta. Es el aspecto genético. Una vida singular puede prescindir de toda individualidad en tanto indeterminada y liberada de toda subordinación, pero en tanto entra en relaciones diferenciales, en tanto es parte de una estructura de lazos ideales, «debe actualizarse en relaciones espacio-temporales diversas, al mismo tiempo en que sus elementos se encarnan actualmente en términos y formas varias». ${ }^{16}$ El nacimiento es, desde esta perspectiva, no la mera reproducción de una especie empírica (humana, por ejemplo) sino la irrupción de la Idea en las cosas.

Podemos ver en el bebe la cantera de la futura fuerza de trabajo, el encadenamiento de las individualidades empíricas según necesidad, pero también las singularidades que lo pueblan, las multiplicidades que lo habitan y persisten más allá de la mecanización de la vida. La biopolítica puede ser la técnica para ajustar la vida a las necesidades del capital. Puede ser el mecanismo para administrar la cantera de reproducción de su mano de obra. Pero también puede ser el arte de captar, en la vida, las multiplicidades que desbordan las condiciones materiales de existencia y pueden hacer nacer tanto vidas individuales como existencias comunitarias (en la medida en que existen ideas correspondientes a los organismos y psiquismos, pero también ideas sociales). Pero para ello es necesario profundizar un poco más en la estructura tripartita de la Idea y la articulación entre su determinación trascendental y su determinación empírica.

14 Ibid.

15 La referencia Nietzsche aparece en «La inmanencia...» (Deleuze, «L'immanence...», op. cit. p. 361), y también en la exposición de la Idea en Diferencia y repetición: «Si la Idea es el diferencial del pensamiento, hay un cálculo diferencial correspondiente a cada Idea... único cálculo 'más allá del bien y del mal'», Deleuze, Différence..., op. cit. p. 235).

16 Deleuze, op. cit. p. 237. 


\section{El nacimiento en Hegel: la idea existente en sí y para sí}

Son grandes las distancias y numerosas las interferencias entre la Idea cuyas aventuras Hegel narra en su Ciencia de la lógica y la que Deleuze le contrapone en Diferencia y repetición. Sin embargo, el minucioso análisis que realiza Hegel de las articulaciones de la Idea nos permite avanzar en su determinación en relación con la vida y el nacimiento. En efecto, si bien en otros lugares de la obra hegeliana la vida se presenta como ciega y carente de pensamiento, ${ }^{17}$ en la última sección de la Ciencia de la lógica aparece como uno de los momentos de la Idea. Nos detendremos en las páginas sobre «el individuo viviente», ${ }^{18}$ donde este autor tan pensado a partir de la problemática de la muerte, le dedica un breve pero muy sustancial desarrollo a la problemática del nacimiento.

Estas páginas se encuentran dentro de la doctrina del concepto, y las distinciones que establecen siguen por tanto sus tres momentos característicos: universalidad, particularidad y singularidad ${ }^{19}$ (aquí, respectivamente, sensibilidad, irritabilidad y reproducción). Intentaremos mostrar que Hegel, al recurrir a la particularidad como término medio, inyecta la causalidad mecánica y las generalizaciones abstractas del intelecto en el corazón mismo del proceso vital y de qué manera es posible encontrar en la letra de su texto los tres momentos deleuzianos: la determinación de la inmanencia (universalidad), lo determinable (receptividad infinita), y la determinación empírica (individualidad). Para ello, según veremos, es preciso desdoblar dos aspectos de lo universal en Hegel (lo determinable y la determinación de la inmanencia).

El nacimiento aparece en el momento de la reproducción. El término podría llevarnos a engaño a la hora de interpretar el texto, y pensar que Hegel está presentando la reproducción de lo mismo (en términos sociales, la reconstitución meramente de las condiciones y relaciones específicas de producción). Sin embargo, esto implicaría pensar cada individuo como independiente o indiferente respecto a otro individuo. Ese es un rasgo de la doctrina del ser (cantidad) - y cuya continuidad al infinito lleva a lo que Hegel denomina progreso infinito o mala infinitud cuantitativa. ${ }^{20}$

Cuando lo viviente se considera como un todo, que consiste de partes, como algo tal que sobre él influyen causas mecánicas o químicas, como un producto mecánico o químico (...) entonces el concepto le queda como extrínseco, lo viviente está considerado como algo muerto. ${ }^{21}$

La muerte es el aspecto empírico, sujeto a la causalidad extrínseca (en términos de «La inmanencia...»: la muerte no es lo propio de una vida, sino lo propio de la vida). Determinaciones empíricas, sin concepto (sin determinación de la inmanencia) son muertas.

17 Cfr. G.W.F. Hegel: Ciencia de la lógica, tomo II, trad. cast. de R. Mondolfo, Buenos Aires, Solar, 1968, p. 261.

18 Cfr. Hegel, op. cit. pp. 483-489.

19 Mondolfo traduce Einzelne por «individualidad», pero lo reemplazaremos en cada caso por la elección de traducción de Valls Plana, «singularidad», para subrayar su distinción respecto al «individuo viviente».

20 «La infinita progresión cuantitativa es en cualquier caso la repetición carente de pensamiento», Hegel, Enciclopedia... op. cit. p. 205. Ver también G.W.F. Hegel: Ciencia de la lógica, tomo I, trad. cast. de R. Mondolofo, Buenos Aires, Solar, 1968, pp. 292-293.

21 Hegel, Ciencia... tomo II, op. cit. pp. 485-486. 
Lo viviente es capaz, como exterioridad, de relaciones empíricas, pero éstas son un modo muerto de concebirlo. Por tanto, la reproducción de lo mismo o reproducción mecánica no caracteriza acabadamente el proceso vital tal como Hegel lo piensa. En tanto momento del concepto (donde las distinciones aquí presentes no pueden valer ni ser aprehendidas como separadas), ${ }^{22}$ la reproducción no es para Hegel esa repetición de lo mismo, sino la vida como algo concreto, como individuo que existe. Se trata de hacer vivir eso que, sin Idea, está muerto:

Con la reproducción, como momento de la individualidad, el viviente se pone como individualidad real, como un ser-por-sí que se refiere a sí mismo, y que, empero, es al mismo tiempo referencia real hacia el exterior (...) Con esto está constituido como la idea existente en sí y para sí. ${ }^{23}$

El viviente como la idea existente en sí y para sí: concepto potente, que marca toda la creatividad ontológica presente en cada nacimiento. Más allá de la mezcla de fluidos y genes, más allá de la gestación y el despliegue embrionario, hay un corte en la mera repetición material. Un viviente se reproduce. Un viviente se hace otro viviente. Entre un viviente y el otro (nuevo) viviente hay un hiato. Y sin embargo ambos vivientes son la misma (una) vida, puesta dos veces: en sí y para sí. Eterna dualidad de la vida, dice Gueroult leyendo a Fichte. En su hijo, el padre se refiere a sí mismo pero como referencia real hacia el exterior (una determinación de la inmanencia que se actualiza como relaciones empíricas). Un padre mira a su bebé. Se refleja en él. «El amor liga luego de la manera más íntima al ser y la imagen que refleja» ${ }^{24}$. Es un espejo por cierto perturbador. ${ }^{25}$ La zoncera del sentido común le dice que se parece a él. Y él quiere (como siempre queremos) creerle al más común de los sentidos. Sería tranquilizador. Pero el espejo ontológico no es la tranquila reflexión que nos devuelve idénticos. El rostro del bebé le devuelve una imagen que, definitivamente, no se parece a él. Y sin embargo es él. Pero no en tanto mero individuo (la semejanza habla de la comparación empírica de individuos, confirma a los individuos en su mero ser empírico). Sino en tanto idea existente en sí y para sí, idea que ambos son, que todos somos, pero sólo como caras de un prisma infinito. Sólo así es individuo real.

22 Hegel, Enciclopedia, op. cit. p. 249.

23 Hegel, Ciencia... op. cit. tomo 2, pp. 489-490 (trad. modificada).

24 Gueroult, op. cit. p. 9.

25 Lacan señalaba el estadio del espejo como la instancia en la cual el niño pequeño enfrenta su imago ideal con la imagen de su descoordinación motriz (fruto de la prematuración específica del nacimiento del hombre) que vive en forma traumática como cuerpo desmembrado y que estará en la génesis de las conductas agresivas del hombre respecto a su semejante ( $c f$. J. Lacan: Ecrits, Paris, Seuil, 1966, pp. 96-97; 112). El espejo perturbador al que nos referimos aquí es muy distinto: no nos enfrenta con la prematuración de nuestras determinaciones empíricas, sino con los acontecimientos de inmanencia que nos pueblan. La fractura constitutiva del yo no es el producto de una falta o una insuficiencia, sino de la conciencia de que yo soy otro, que soy encarnación de una Idea y sus singularidades pre-individuales, que nazco porque el tejido de la realidad empírica se quiebra. 


\section{La mediación como maldición: dolor, negatividad, sufrimiento y muerte}

La reproducción hegeliana carga sin embargo, en la dialéctica del individuo viviente, con un estigma de la reproducción mecánica. En efecto, de acuerdo a la dinámica de la Aufhebung característica de su dialéctica, el concepto no sólo supera sino que también conserva el momento de la reflexión, bajo la forma de la particularidad: en tanto particular la autodeterminación del viviente es «su limitarse, por cuyo medio se refiere a lo exterior como una objetividad presupuesta y en acción recíproca con ella». ${ }^{26} \mathrm{El}$ individuo es así parte de una especie, al lado de otras especies de seres vivientes. Desde esta óptica, el individuo viviente encarna la lógica de la reproducción mecánica. Y, si bien se trata, según Hegel mismo lo reconoce, de un momento abstracto, ya superado, no deja de ocupar un lugar estratégico en la concepción hegeliana del individuo viviente: término medio entre la universalidad y la individualidad. Este lugar estratégico es el que se trata de cuestionar. La articulación entre la Idea como universal y el individuo viviente como singular queda en manos de esta instancia abstracta que no es, en realidad, más que la generalización a partir de las semejanzas de la percepción realizada por el entendimiento. ${ }^{27}$ Lo más vacío no puede articular.

La particularidad sostiene en el seno de la vida la carga de muerte, negatividad y dolor característica de la reproducción mecánica. Quizás por ello Hegel concibe la reproducción, desde el punto de vista del individuo que se reproduce, como desdoblamiento, contradicción, dolor:

El concepto se ha desdoblado así en su absoluta desigualdad consigo mismo, y, por cuanto es también la absoluta identidad en esta división en dos, el viviente es así por sí mismo este desdoblamiento, y tiene el sentimiento de esta contradicción, que es el dolor. Por consiguiente el dolor es el privilegio de las naturalezas vivientes; éstas, siendo el concepto existente, son una realidad de la fuerza infinita, es decir que son en sí la negatividad de sí mismas, y que esta negatividad suya existe por ellas, y que ellas se conservan en su ser-otro. - Cuando se dice que la contradicción no puede ser pensada [tal declaración es errónea, porque] la contradicción es más bien una existencia real en el dolor del viviente. ${ }^{28}$

Parirás con dolor. Ese dolor, ese desgarramiento, parece confirmar el aspecto ineludiblemente atormentado de la filosofía de Hegel. Pareciera que, a través del dolor, el nacimiento queda subordinado a la muerte. El dolor es la marca en el nacimiento de la negatividad y la finitud que arrastramos en tanto existentes en el mundo. El dolor es la marca, en el mismo momento de la generación de la vida, de la muerte. Sólo en «la muerte de la primera individualidad» ${ }^{29}$ puede el proceso de la vida progresar. El estremecimiento del padre que mira a su bebé no proviene desde esta perspectiva del surgimiento de la idea existente en sí y para sí, sino de la certeza de su propia muerte en la reproducción. Un dolor espiritual mucho más desgarrador que el del más físicamente tormentoso de los partos.

26 Hegel, Ciencia... tomo 2, op. cit. p. 488.

27 Cfr. Hegel, op. cit. p. 250.

28 Hegel, Ciencia... tomo 2, op. cit. p. 491.

29 Hegel, op. cit. p. 483. 
Sin embargo, Hegel mismo había ya dicho que el viviente considerado como algo muerto es aquel considerado como una cadena de causas mecánicas al cual «el concepto le queda como extrínseco». Esta pobreza del concepto de la causalidad extrínseca se repite en el momento de la particularidad del individuo viviente: el individuo considerado como especie, ¿no es después de todo el producto muerto de la reflexión extrínseca del entendimiento? Causalidad extrínseca - especie — dolor — muerte individual. La saga del momento negativo asfixia toda la positividad del nacimiento. Es la negatividad, la determinación como negación, en suma, la manera en la que la reflexión (el entendimiento) se representa a la diferencia y que el concepto arrastra, carga sobre sí bajo el estigma de la Aufhebung.

Pareciera que esa determinación solamente puede provenir de un elemento negativo, contrapuesto. Que la determinación debe provenir de esa absoluta negatividad que la universalidad lleva en sí. En efecto, a diferencia de la inmediatez del ser, la inmediatez del concepto (esto es, la universalidad) contiene en sí la negatividad merced al pasaje por la esencia. La lógica de la esencia, que no es otra cosa que el repaso de las categorías del entendimiento, aparece así como el cáncer de la filosofía hegeliana. La dialéctica no puede liberarse de las esencialidades o determinaciones de la reflexión (identidad, negación y contradicción). Merced a la isología de las categorías del concepto con las de la esencia, ${ }^{30}$ Hegel sólo puede concebir lo universal como identidad y la diferencia como momento negativo, segundo. Así, el movimiento mismo del sistema no es más que un poner que no pone nada, porque sólo se pone a sí mismo (como el fundamento). ${ }^{31}$ La reflexión de la esencia postula un espejo ontológico que repite lo idéntico a sí mismo. Pero la universalidad de la Idea («ella es la sustancia absoluta del espíritu como naturaleza, lo universal») ${ }^{32}$ muestra su verdadera naturaleza perturbadora: ser el abismo de la repetición de la diferencia.

\section{Liberar a Hegel de Hegel mismo}

¿Será posible, en la saga de la caracterización de Löwith del proyecto de los jóvenes hegelianos «liberar a Hegel de Hegel mismo», ${ }^{33}$ y poder pensar una articulación en todo positiva del universal y el individual? Tal es la propuesta deleuziana:

La forma de la repetición en el eterno retorno, es la forma brutal de lo inmediato, la del universal y el singular reunidos, que destrona toda ley general, hace fundir las mediaciones, perecer a los particulares sometidos a la ley. ${ }^{34}$

30 Hegel señala la isología universalidad/identidad, particularidad/diferencia en su Enciclopedia, op. cit. p. 249.

31 «Cuando preguntamos por el fundamento de las cosas (...) queremos ver la cosa indiferentemente duplicada, una vez en su inmediatez y una segunda vez en su fundamento», Hegel (Enciclopedia, op. cit. p. 248). Ese es el movimiento que Deleuze critica: «La diferencia es el fondo, pero únicamente el fondo para la manifestación de lo idéntico. El círculo de Hegel no es el eterno retorno, sino solamente la circulación infinita de lo idéntico a través de la negatividad», Deleuze, op. cit. p. 71. Esta crítica afecta en realidad más a la lógica de la esencia que a la del concepto, y sólo es aplicable a Hegel en la medida en que las determinaciones de la reflexión persisten en la Idea.

32 Hegel, Enciclopedia, op. cit. p. 340.

33 Cfr. K. Löwith: De Hegel a Nietzsche, trad. E. Estiú, Buenos Aires, Katz, 2008, p. 101.

34 Deleuze, op. cit. p. 15. 
Reunir lo universal y lo singular con prescindencia de los particulares. Por supuesto, el riesgo de eliminar la mediación es el antes mencionado: que la filosofía de la diferencia se transforme en indiferencia (sea por la fusión de los elementos o el establecimiento de una brecha ontológica entre los planos). Pero Deleuze sólo quiere eliminar la mediación en la medida en que implica lo particular y, con él, la carga de negatividad, dolor y muerte. No se trata de limitarse a dos valores lógicos (universal y singular, o lo indeterminado y la determinación) que se vincularían de forma inmediata, sino de introducir un tercer valor que no provenga de la reflexión. Deleuze dice: es necesario, como quería Kant, que un tercer valor lógico se agregue a lo indeterminado y la determinación: lo determinable. ${ }^{35} \mathrm{Y}$ este valor aparece en el texto de Hegel, cuando considera la universalidad del individuo viviente:

[La vitalidad] en primer lugar es universalidad, el puro vibrar solamente en sí misma de la vitalidad, es decir, la sensibilidad (...) La sensibilidad es el ser-en-sí, no como simplicidad abstracta, sino como una receptividad infinita determinable, que en su determinación no se convierte en un múltiple y un externo, sino que está reflejada absolutamente en sí (...) La sensibilidad puede así considerarse como la existencia del alma existente en sí, pues acoge en sí toda exterioridad, haciéndola, empero, volver a la completa simplicidad de la universalidad igual a sí misma. ${ }^{36}$

Como simple universalidad, la vida es indeterminada. Pero es también determinable, mediante una determinación reflejada absolutamente en sí, no sujeta a la exterioridad. Se trata pues de una determinación que no actúa como negatividad ni como contraposición. Es una determinación de la inmanencia: «el objeto diferente [das differente Objekt] posee una determinación inmanente que constituye su naturaleza y en la cual tiene existencia». ${ }^{37}$ En torno a lo determinable como determinación de la inmanencia se esboza una dialéctica no sometida a la negatividad como la pensó Deleuze:

Por dialéctica, no entendemos de ninguna manera algún tipo de circulación de representaciones opuestas que las haría coincidir en la identidad del concepto, sino el elemento del problema (...) Los lazos ideales constitutivos de la Idea problemática (dialéctica) se encarnan entonces aquí en relaciones reales. ${ }^{38}$

Las relaciones diferenciales son relaciones dialécticas. Las relaciones en la Idea no son por ello de oposición. No es necesario traer a la mesa la negatividad. Es totalmente posible pensar la determinación de la inmanencia como un haz de relaciones diferenciales. Relaciones de inmanencia, que no se confunden con las relaciones empíricas de las cuales, sin embargo, son el elemento genético. La Differenz está así en la base de la Unterscheidung. ${ }^{39}$ Ese es, después de todo, el gran aporte de los «post-kantianos» de acuerdo a Deleuze: repro-

35 cfr: Deleuze, op. cit. p. 116.

36 Hegel, Ciencia... tomo 2, op. cit. p. 488.

37 Hegel, Enciclopedia, op. cit. p. 357.

38 Deleuze, op. cit. pp. 231-232.

39 Valls Plana señala que el término different debe interpretarse como opuesto a gleichgültig (= indiferente). Se distingue así de lo meramente distinto (unterschieden). Cfr. Hegel, Enciclopedia, op. cit. p. 275, nota. 
char a Kant haberse quedado en el punto de vista del condicionamiento sin alcanzar el de la génesis..$^{40}$ Cuando Hegel habla de una «receptividad infinita determinable», ¿no puede pensarse esa receptividad infinita determinable de la vida como lo que da lugar a la posibilidad de una universalidad perfectamente determinada? Una absoluta diferencia, indeterminada pero determinable. Si la universalidad no se considerara isológica con la identidad, sino que es ya en sí misma diferencia, no es necesario «añadirle» el momento de la diferencia como particularidad: «Hegel sustituye la verdadera relación del singular y del universal en la Idea por la relación abstracta el particular con el concepto en general». ${ }^{41} \mathrm{Si}$, como propone Deleuze, pensamos que la diferencia está en lo universal, y que lo universal es diferencia, entonces la relación universal-singular no debe pasar por la abstracción de la particularidad, sino que puede operarse directamente a partir de las diferencias constitutivas de lo universal. Ese es el sentido de la afirmación deleuziana: «la idea es un universal concreto».42

\section{Los pliegues de la Mannigfaltigkeit}

En la Idea como universal concreto la sensibilidad no se opondría a la multiplicidad, sino que se identificaría con ella. Hegel en algunos desarrollos se asoma a este aspecto de la multiplicidad:

Multiplicidad [Mannigfaltigkeit] que por cierto es completa, pero que, por lo restante, es indeterminada, es decir, carente de relación [Verhältinlose] (...) Esta determinación indeterminada es esencial al objeto, éste representa en sí mismo una tal multiplicidad, y tiene, por ende, que ser considerado como un compuesto, como un agregado.- Sin embargo, no está constituida de átomos. ${ }^{43}$

Se trataría de una multiplicidad que no estaría constituida de átomos vinculados extrínsecamente entre sí. Carente pues de relaciones empíricas (Verhältnis). Es, por tanto, empíricamente indeterminado. Pero posee una «determinación indeterminada», dice Hegel, que podría vincularse con la determinación de la inmanencia deleuziana. Esta vinculación se observa en el concepto que, en su singular interpretación de Leibniz, Deleuze llamó el pliegue:44

La materia presenta una textura infinitamente porosa, esponjosa o cavernosa sin vacío, siempre una caverna dentro de una caverna (...) [Las partes] no se separan en partes de partes, sino que se dividen al infinito en pliegues cada vez más pequeños que mantienen una cierta cohesión. Así el laberinto del continuo no es una línea que se disolvería en puntos independientes, como la arena fluida en granos, sino como una tela o una hoja de papel que se divide en pliegues al infinito o se descompone en movimientos curvos (...) Siempre un pliegue en pliegue, siempre una caverna dentro de una caverna. ${ }^{45}$

40 Cfr. Deleuze, op. cit. p. 221.

41 Deleuze, op. cit. p. 18.

42 Deleuze, op. cit. p. 228.

43 Hegel, Ciencia... op. cit. tomo 2, p. 419.

44 En alemán, el pliegue es Die Falte, presente en la Mannigfaltigkeit.

45 Deleuze, op. cit. p. 9. 
Una multiplicidad deleuziana no es un conjunto de elementos ligados por relaciones extrínsecas. Las singularidades constitutivas de la Idea no son átomos, sino pliegues minúsculos que no cesan de hacerse deshacerse. ${ }^{46} \mathrm{El}$ concepto de pliegue, permite concebir una materia infinitamente porosa que no es, como lo creyó Hegel, una mera fantasía del entendimiento, ${ }^{47}$ sino justamente aquello que derrumba las categorías del entendimiento que, en la ontología hegeliana, persisten como las determinaciones de la reflexión. La materia concebida como textura infinitamente porosa plagada de pliegues permite comprender de qué manera las relaciones de las singularidades en la Idea pueden encarnarse en determinaciones empíricas, de qué manera las relaciones en lo universal pueden dar nacimiento a las relaciones empíricas.

Hegel objeta: la multiplicidad es indeterminada. ${ }^{48}$ Lo cual no sólo no es un defecto sino una necesidad: sólo lo indeterminado puede ser novedoso. Lo completamente determinado carece de posibilidad de novedad. Es justamente la diferencia gramatical entre el pronombre determinado y el indeterminado: el indeterminado (una vida) señala la introducción de un sustantivo nuevo en determinado contexto, mientras el determinado ( $l a$ vida) implica que sabemos ya de qué vida estamos hablando, que no hay novedad, nada que explorar. Pero si lo indeterminado no pudiera nunca determinarse, permanecería en el terreno de lo meramente posible: la promesa de una novedad que nunca llega, que permanece como deber ser. En la Idea deleuziana existe un aspecto indeterminado, sí, pero determinable mediante las relaciones recíprocas que están en la naturaleza misma de los pliegues o singularidades (que, no siendo átomos, sólo existen en su relación). A través de la relación recíproca los pliegues se transforman en elementos genéticos: ${ }^{49}$ «la determinación recíproca de las diferenciales $\left(\frac{d y}{d x}\right)$ acarrea la determinación completa del objeto». ${ }^{50}$ La fórmula $\left(\frac{d y}{d x}\right)$, expresa la relación recíproca de las singularidades o pliegues, subrayando que tanto $d y$ como $d x$ son absolutamente indeterminados fuera de la relación (fuera de la relación no son nada), pero perfectamente determinados dentro de ella:

$D x$ y $d y$ están totalmente indiferenciados [indifférenciés, determinación empírica], tanto en el particular como en lo general, pero totalmente diferentiados [différentiés, determinación de inmanencia] en el universal y por él..$^{51}$

Hegel dedicó largas reflexiones a la cuestión de la relación diferencial en la última parte del estadio «cantidad» de la doctrina del ser (reflexiones ya extensas en la primera edición de 1812, y que se vieron largamente incrementadas en la de 1830). ${ }^{52}$ En la relación diferencial, de acuerdo a Hegel, la cualidad y la cantidad encuentran su punto de disolución y superación mutua. Los desarrollos respecto al cálculo diferencial en la Ciencia de la lógica son mucho más ricos que la sección que lo sigue (la medida) cuya profundidad, en suma, deriva

46 Cfr. G. Deleuze: Le pli: Leibniz et le barroque, Paris, Minuit, 1988, p. 124.

47 Cfr. Hegel, Enciclopedia, op. cit. p. 224.

48 Cfr. Hegel, Ciencia... tomo 2, op. cit. p. 419.

49 Sobre el valor genético del pliegue, cfr. Deleuze, op. cit. pp. 20, 32, 49, 114 y 118.

50 Deleuze, Différence... op. cit. p. 118.

51 Deleuze, op. cit. p. 223.

52 Cfr. Hegel, Ciencia... tomo 1, op. cit. pp. 352-387. 
directamente de la posibilidad de una relación diferencial ${ }^{53}$. En contraste con el minucioso desarrollo dedicado al cálculo diferencial, el pasaje a la esencia a través de la medida aparece como mucho más precipitado. In extremis, se podría pensar si no sería posible pensar que la relación diferencial es ya el pasaje al concepto y que la doctrina de la esencia no es un momento necesario sino más bien un estudio de las imágenes del pensamiento que debería considerarse un prolegómeno de la filosofía. ${ }^{54}$

\section{Biopolítica como relación diferencial}

La relación diferencial $d y / d x$ nos arrastra al verdadero corazón del pensamiento deleuziano de la biopolítica. Ocurre que esta fórmula es utilizada por Deleuze (junto con Guattari) para caracterizar al capitalismo en El Anti-Edipo: «Es la relación diferencial $d y / d x$, donde Dy deriva de la fuerza de trabajo y constituye la fluctuación del capital variable, y donde Dx deriva del capital mismo y constituye la fluctuación del capital constante», ${ }^{55}$ en una definición que se liga a una de las presentaciones foucaultianas de la biopolítica:

El ajuste de la acumulación de los hombres sobre la del capital, la articulación del crecimiento de los grupos humanos con la expansión de las fuerzas productivas y la repartición diferencial de la ganancia, fueron, por una parte, hechos posibles por el ejercicio del biopoder bajo la forma de sus procedimientos múltiples. ${ }^{56}$

La vecindad de ambas presentaciones se funda en que ambas están referidas a la caracterización del capitalismo como relación o encuentro entre flujos libres de trabajadores y capital realizada por Marx en El Capital ${ }^{57}$. Deleuze retoma en El Anti-Edipo los desarrollos de Diferencia y repetición en referencia a Leibniz, donde la relación diferencial aparece como el principio de razón suficiente que garantiza la convergencia y composibilidad de las series, atando la multiplicidad de los pliegues a un principio de orden. $D y / d x$ es así «la razón suficiente como fundamento que selecciona, es decir que elige el mundo que es el mejor» ${ }^{58}$ (el principio de la representación órgica de lo infinitamente pequeño, que garantiza la identidad de la multiplicidad de diferencias). ${ }^{59}$ En ese sentido la ontología de Leibniz es la del capitalismo, intentando elevar este modo de organización social históricamente determinado al estatus del mejor de los mundos posibles. ${ }^{60}$

53 Esta tensión se observa también en el quimismo, que es superado precipitadamente por la teleología. Cfr. Hegel, Enciclopedia, op. cit. pp. 276-277.

54 «Este estudio de las imágenes del pensamiento, que uno llamaría noología, sería el prolegómeno de la filosofía», G. Deleuze: Pourparlers, Paris, Minuit, 1990, p. 203.

55 G. Deleuze y F. Guattari, L'anti-Oedipe, Paris, Minuit, 1972, p. 270.

56 Foucault, op. cit. pp. 185-186. Ver también M. Foucault: «Entretien avec Michel Foucault», en: Dits et écrits, Paris, Gallimard, 2001, p. 153.

57 Cfr. K. Marx, El Capital I, 3, trad. cast. Pablo Scaron, Buenos Aires, Siglo XXI, 1975, pp. 892-893.

58 Deleuze, Différence, op. cit. p. 69.

59 Sobre la representación órgica de lo infinitamente pequeño, cfr. Deleuze, op. cit. pp. 66-69.

60 Sobre la relación entre el capitalismo y la ontología de Leibniz tal como la interpreta Deleuze, $c f$. J. Ferreyra, L'ontologie... op. cit.. 
Pero el lazo entre $d y$ como derivado de la fuerza de trabajo y $d x$ como derivado del capital mismo no puede ser sostenido en la realidad efectiva por la voluntad divina. Allí es donde entra la biopolítica: su rol es sostener condiciones del capitalismo, modulando las necesidades de repartición diferencial de la ganancia. En ese contexto, la reproducción sólo puede ser mecánica, un mero instrumento para la articulación del crecimiento de los grupos humanos con la expansión de las fuerzas productivas:

El concepto marxista de reproducción designa la reconstitución permanente de las condiciones y de las relaciones de producción, que efectúa todo proceso social de producción y que hace del modo de producción una estructura durable (...) La reproducción en El Capital - Marx, en el libro I, sección II, comienza el estudio de la relación propiamente capitalista por un análisis que muestra que el «círculo» del capital, A-M-A presenta un verdadero proceso cíclico que reproduce sus condiciones iniciales. ${ }^{61}$

Desde la perspectiva clásica de la reproducción, la biopolítica implicaría el conjunto de tecnologías que permiten que la relación de producción característica del capitalismo se constituya como una estructura durable. Garantizar el círculo del capital. Quizás los diagnósticos más lúgubres de la biopolítica, los usos más críticos del término, la insistencia en postular la necesidad de una resistencia a la biopolítica se basen en su identificación con la organización capitalista de la sociedad. De la misma manera, la posibilidad de una lectura afirmativa depende de la posibilidad de pensar una biopolítica más allá del capital. Esa misma ambivalencia puede encontrarse en el uso de la fórmula $d y / d x$ : por una parte, un uso restringido, de acuerdo al cual es utilizada para definir al capitalismo y el principio leibniziano de razón suficiente. Pero, por otra parte, un uso ampliado en el seno de la teoría de la Idea. En este caso, se encuentra libre de las ataduras de la axiomática de Leibniz y de la efectuación de una mera reproducción de lo mismo. Dy / dx es la relación diferencial en la Idea que permite concebir a ésta como la fuente perpetua de creación de la realidad. El nacimiento es reproducción, pero no como la caracteriza el marxismo clásico sino tal como la postuló Hegel: como idea existente en sí y para sí. No está entonces condenado a la repetición de lo mismo sino, por el contrario, ontológicamente ligado a la repetición de la diferencia.

Se abre así la posibilidad de pensar la génesis de una nueva formación social dentro del capitalismo. No quedamos atrapados en el círculo del capital, sino que nuestra sociedad tiene la capacidad de ponerse como una individualidad real, como constituyendo la idea existente en sí y para sí. Ya no suma de individuos, ni individuos que sólo son, que sólo existen en tanto expresiones de este mundo, sino la posibilidad de una irrupción perturbadora, transformante. El nacimiento en la biopolítica. Así, la caracterización más general de la biopolítica («hacer vivir o rechazar hacia la muerte»), encierra promesas de exceder las más restringidas. No sólo un mecanismo para asegurar, entonces, el acoplamiento de flujos de capital y trabajo en permanente expansión. Sino someter las relaciones empíricas a la

61 J. Bidet: «Reproduction», en: G. Benussan y G. Labica (eds.): Dictionnaire critique du marxisme, Paris, PUF, 1999, pp. 997-998. 
potencia de las relaciones de inmanencia (hacer vivir). Inscribir en lo real las posibilidades de creación de lo virtual, quebrando la sucesión de la causalidad mecánica (rechazar hacia la muerte las relaciones existentes de producción). Abrir la posibilidad de conformar una nueva realidad, no menos racional que la actual. Hijo monstruoso del capitalismo que desviaría las energías del mundo hacia nuevos fines. De pronto una nueva organización social estará ahí entre nosotros. Un nuevo Estado, que no será a imagen y semejanza de los estados modernos.

Un padre mira a su bebé. Se refleja en él. Espejo singular, perturbador, desformante. La zoncera del sentido común le dice: «se parece a vos». Y él quiere (como siempre) creerle. Sería tranquilizador. No obstante, el espejo ontológico le devuelve una imagen que, definitivamente, no se parece a él. Y sin embargo es él. Pero no en tanto individuo (sólo los individuos se parecen). Sino en una sonrisa, un gesto, una mueca que no son caracteres subjetivos. Sino en tanto están atravesados de una vida inmanente que es pura potencia. Sino en tanto las singularidades de ambos llenan un mismo plano de inmanencia. Sino en tanto idea existente en sí y para sí. Idea que ambos son, que todos somos, pero sólo como faces de un prisma infinito. 